\title{
Validated RP-HPLC Method for the Determination of Buspirone in Pharmaceutical Formulations
}

\author{
M. V. Basaveswara Rao, ${ }^{1}$ A. V. D. Nagendrakumar, ${ }^{2}$ Sushanta Maiti, ${ }^{1}$ and Guttikonda Raja ${ }^{1}$ \\ ${ }^{1}$ Department of Chemistry, Krishna University, Machilipatnam 521001, A.P, India \\ ${ }^{2}$ Department of Chemistry, GITAM University, Visakhapatnam 530045, A.P, India
}

Correspondence should be addressed to M. V. Basaveswara Rao, vbrmandava@yahoo.com

Received 10 June 2011; Revised 8 July 2011; Accepted 31 July 2011

Academic Editor: Irene Panderi

Copyright (C) 2011 M. V. Basaveswara Rao et al. This is an open access article distributed under the Creative Commons Attribution License, which permits unrestricted use, distribution, and reproduction in any medium, provided the original work is properly cited.

A simple, selective, linear, precise, and accurate RP-HPLC method was developed and validated for the rapid assay of the Buspirone in tablet dosage form. Isocratic elution at a flow rate of $1.0 \mathrm{~mL} / \mathrm{min}$ was employed on a symmetry $\mathrm{C} 18(250 \times 4.6 \mathrm{~mm}, 5 \mu \mathrm{m}$ in particle size) at ambient temperature. The mobile phase consisted of water: acetonitrile: methanol $45: 35: 20$ (V/V). The UV detection wavelength was $210 \mathrm{~nm}$, and $20 \mu \mathrm{L}$ sample was injected. The retention time for the Buspirone was $7.057 \mathrm{~min}$. The percentage RSD for precision and accuracy of the method was found to be less than $2 \%$. The method was validated as per the ICH guidelines. The method can be successfully applied for the routine analysis of Buspirone in tablet dosage form.

\section{Introduction}

Buspirone is a psychotropic drug used primarily as an anxiolytic, specifically for generalized anxiety disorder; it belongs to the class of compounds known as azaspirodecanediones. Buspirone has been shown to improve spatial learning and memory after traumatic brain injury (TBI) $[1,2]$. Buspirone shares some of the properties of the benzodiazepines $[3,4]$ and the neuroleptics, as well as demonstrating other pharmacological actions. After the treatment with buspirone, no withdrawal symptoms developed [5]. Buspirone does not improve discontinuation rates and does not decrease the severity of withdrawal symptoms [6]. Buspirone functions as a serotonin 5$\mathrm{HT}_{1 \mathrm{~A}}$ receptor partial agonist [7]. It is this action that is thought to mediate its anxiolytic and antidepressant effects. Additionally, it functions as a dopamine $\mathrm{D}_{2}$, as well as $\alpha_{1}$, and $\alpha_{2}$-adrenergic receptor antagonist to a lesser degree, though these properties are generally undesirable in an anxiolytic and likely only contribute to side effects. Buspirone, 8-[4-[4-(2-pyrimidyl)-1-piperazinyl]butyl]-8azaspiro[4,5]decan-7,9-dione, is synthesized by the reaction of 1-(2-pyrimidyl)-4-(4-aminobutyl) piperazine with 8-ox- aspiro[4,5]decan-7,9-dione. In turn, 1-(2-pyrimidyl)-4(4-aminobutyl)piperazine is synthesized by the reaction of 1(2-pyrimidyl) piperazine with 4-chlorobutyronitrile, giving 4-(2-pyrimidyl)-1-(3-cyanopropyl)piperazine, which is hydrogenated over Raney nickel catalyst. Buspirone has formula $\mathrm{C}_{21} \mathrm{H}_{31} \mathrm{~N}_{5} \mathrm{O}_{2}$ and Mol. mass $385.50 \mathrm{~g} / \mathrm{mol}$ (Figure 1).

\section{Experimental}

2.1. Chemicals and Reagents. HPLC grade acetonitrile and methanol were purchased from Merck Specialities Pvt. Ltd.

2.2. Instrumentation and Analytical Conditions. The analysis of drug was carried out on a PEAK HPLC system equipped with a reverse phase C18 column $(210 \times 4.6 \mathrm{~mm}, 5 \mu \mathrm{m}$ in particle size), a LC-P7000 isocratic pump, a $20 \mu \mathrm{L}$ injection loop, and a LC-UV7000 absorbance detector and running on PEAK Chromatographic Software version 1.06. Isocratic elution with water: acetonitrile: methanol $45: 35: 20(\mathrm{~V} / \mathrm{V})$ $\left(\mathrm{P}^{H}-5.5\right)$ was used at a flow rate of $1.0 \mathrm{~mL} / \mathrm{min}$. The mobile phase was prepared freshly and degassed by sonicating for 5 min. before use. 


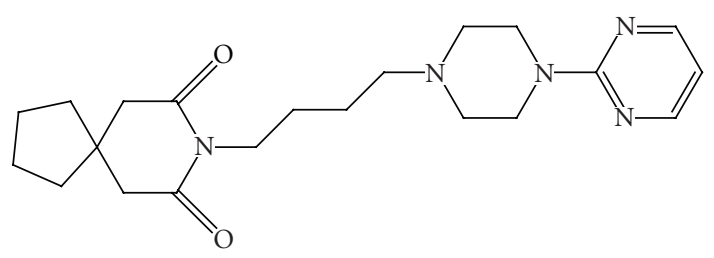

FIgURE 1: Chemical structure of Buspirone.

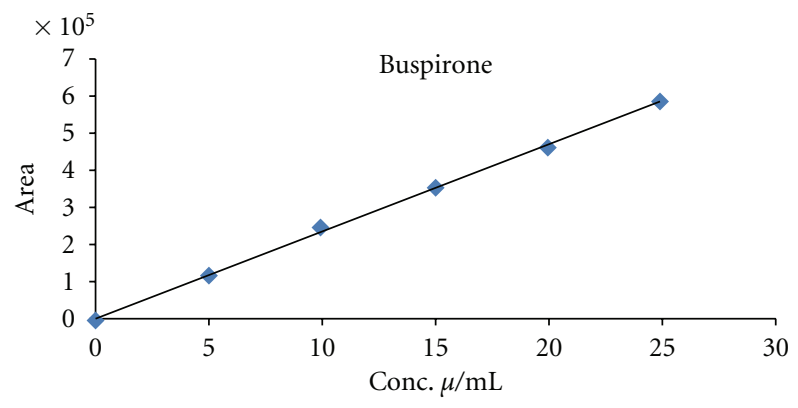

Figure 2

2.3. Stock and Working Standard Solutions. $10 \mathrm{mg}$ of Buspirone working standard was transferred into a $10 \mathrm{~mL}$ volumetric flask, and diluent was added and sonicated to dissolve it completely, and then the volume was made up to the mark using the same solvent. Further $1 \mathrm{~mL}$ of the above stock solution was pipette into a $10 \mathrm{~mL}$ volumetric flask and diluted up to the mark with diluent and was filtered through $0.45 \mu \mathrm{m}$ nylon filter paper. From the above filtered sample $30 \mu \mathrm{g} / \mathrm{mL}$ solution was prepared. The calibration curve was plotted with the five concentrations of the $5.0-30.0 \mu \mathrm{g} / \mathrm{mL}$ working standard solutions. Calibration solutions were prepared daily and analyzed immediately after preparation.

2.4. Assay of Buspirone Tablets. $20 \mathrm{mg}$ of Buspirone tablets were weighed and the average weight was calculated. An Accurately weighed amount of $10 \mathrm{mg}$ of Buspirone was transferred into a $10 \mathrm{~mL}$ volumetric flask. Diluent added to buspirone and sonicated to dissolve buspirone in diluent and add diluent up to the mark of volumetric flask. The constituents were mixed well and filtered through $0.45 \mathrm{um}$ filter. Further $1 \mathrm{~mL}$ of the above stock solution was pipetted out into a $10 \mathrm{~mL}$ volumetric flask and diluted up to mark with diluent. From the above filtered sample $30 \mu \mathrm{g} / \mathrm{mL}$ solution was prepared. An aliquot of this solution was injected into HPLC system. Peak area of Buspirone was measured for the determination.

2.5. Validation Procedure. The objective of the method validation is to demonstrate that the method is suitable for its intended purpose as it is stated in $\mathrm{ICH}$ guidelines. The method was validated for linearity, precision (repeatability and intermediate precision), accuracy, specificity, stability, and system suitability. Standard plots were constructed with five concentrations in the range of $05.0 \mu \mathrm{g} / \mathrm{mL}$ to $30.0 \mu \mathrm{g} / \mathrm{mL}$ prepared in triplicates to test linearity. The peak area of
Buspirone was plotted against the concentration to obtain the calibration graph. The linearity was evaluated by linear regression analysis that was calculated by the least square regression method. The precision of the assay was studied with respect to both repeatability and intermediate precision. Repeatability was calculated from five replicate injections of freshly prepared Buspirone test solution in the same equipment at a concentration value of $100 \%(30 \mu \mathrm{g} / \mathrm{mL})$ of the intended test concentration value on the same day. The experiment was repeated by assaying freshly prepared solution at the same concentration additionally on two consecutive days to determine intermediate precision. Peak area of the Buspirone was determined and precision was reported as \%RSD. Method accuracy was tested (\% recovery and \%RSD of individual measurements) by analyzing sample of Buspirone at three different levels in pure solutions using three preparations for each level. The results were expressed as the percentage of Buspirone recovered in the samples. Short-term stability was tested for sample solution at ambient temperature $\left(20 \pm 10^{\circ} \mathrm{C}\right)$ for three days. In order to confirm the stability of both standard solutions at $100 \%$ level and tablet sample solutions, both solutions protected from light were reinjected after 24 and 48 hours at ambient temperature and compared with freshly prepared solutions.

\section{Results and Discussion}

3.1. Optimization of the Chromatographic Conditions. Proper selection of the stationary phase depends upon the nature of the sample, molecular weight, and solubility. The drug Buspirone in polar compounds preferably analyzed by reverse phase columns. Among $\mathrm{C}_{8}$ and $\mathrm{C}_{18}, \mathrm{C}_{18}$ column was selected. Nonpolar compound is very attractive with reverse phase columns. So the elution of the compound from the column was influenced by polar mobile phase. Mixture of water: acetonitrile: methanol was selected as mobile phase, and the effect of composition of mobile phase on the retention time of Buspirone was thoroughly investigated. The concentrations of the water: acetonitrile: methanol were optimized to give symmetric peak with short run time.

\subsection{Method Validation}

3.2.1. Linearity. Five-point graph was constructed covering a concentration range $5.0-25.0 \mu \mathrm{g} / \mathrm{mL}$ (three independent determinations were performed at each concentration.) Linear relationships between the peak area signal of Buspirone and the corresponding drug concentration were observed. 
TABLE 1: Regression analysis of the calibration curve.

\begin{tabular}{lc}
\hline Parameters & Values \\
\hline Calibration range $(\mu \mathrm{g} / \mathrm{mL})$ & $5-25$ \\
Slope & 22999.366 \\
Intercept & 10224.49 \\
Correlation coefficient $\left(r^{2}\right)$ & 0.999 \\
\hline
\end{tabular}

TABLE 2: System suitability and validation parameters.

\begin{tabular}{lc}
\hline Parameters & Results \\
\hline Theoretical plates $(N)$ & 5378.36 \\
Retention time $(\mathrm{min})$ & 7.057 \\
Asymmetric factor & 1.09 \\
LOD $(\mathrm{ng} / \mathrm{mL})$ & 20 \\
LOQ $(\mathrm{ng} / \mathrm{mL})$ & 65 \\
Accuracy $(\%)$ & 98.52 \\
R.S.D. $(\%)$ & 1.352 \\
\hline
\end{tabular}

TABLE 3: Assay results of tablet formulation.

\begin{tabular}{lcc}
\hline Formulation & Labelled claim $(\mathrm{mg})$ & \% BUSPIRONE of tablet \\
\hline BUSPIN & $10 \mathrm{mg}$ & $96.72 \%$ \\
\hline
\end{tabular}

The standard deviation of the slope and intercept were low. The statistical analysis of calibration is shown in Table 1.

3.2.2. Precision. The validated method was applied for the assay of commercial tablets containing Buspirone. Sample was analyzed for five times after extracting the drug as mentioned in assay sample preparation of the experimental section. The results presented good agreement with the labeled content. Low values of standard deviation denoted very good repeatability of the measurement. Thus, it was shown that the equipment used for the study was correct, and hence the developed analytical method is highly repetitive. For the intermediate precision, a study carried out by the same analyst working on the same day on three consecutive days indicated a RSD of 1.352. This indicates good method precision.

3.2.3. Stability. The stability of Buspirone in standard and sample solutions containing different solutions was determined by storing the solutions at ambient temperature (20 $\pm 10^{\circ} \mathrm{C}$ ). The solutions were checked in triplicate after three successive days of storage, and the data were compared with freshly prepared samples. In each case, it is noticed that solutions were stable for $48 \mathrm{hrs}$, as during this time the results did not decrease below 98\%. This denotes that Buspirone is stable and standard for at least 2 days at ambient temperature. Results are furnished in Table 2.

3.2.4. System Suitability. System suitability tests were carried out on freshly prepared standard stock solutions of Buspirone and were calculated by determining the standard deviation of Buspirone standards by injecting standards in five replicates at 6 mins intervals and the values were recorded. The system suitability parameters, like capacity factor, asymmetry factor, tailing factor, and number of theoretical plates were calculated. It was observed that all the values are within the limits (Table 1). The statistical evaluation of the proposed method revealed its good linearity, reproducibility, and its validation for different parameters and leads us to the conclusion that it could be used for the rapid and reliable determination of Buspirone in tablet formulation. The results are furnished in Table 2 .

\section{Conclusion}

A RP-HPLC method has been developed and validated for the determination of Buspirone in tablet dosage form. This method is simple, rapid, accurate, precise, and specific. Its chromatographic runtime of 10 mins allows the analysis of a large number of samples in short period of time. Therefore, it is suitable for the routine analysis of Buspirone in pharmaceutical dosage forms (Figure 2, Table 3).

\section{References}

[1] A. E. Kline, A. S. Olsen, R. D. Zafonte, C. N. Sozda, H. A. Aslam, and J. P. Cheng, "Brain injury delayed and chronic buspirone treatment after experimental traumatic brain injury enhances spatial acquisition," Archives of Physical Medicine and Rehabilitation, vol. 88, no. 9, article E6, 2007.

[2] J. P. Cheng, A. N. Hoffman, R. D. Zafonte, and A. E. Kline, "A delayed and chronic treatment regimen with the 5HT1A receptor agonist 8-OH-DPAT after cortical impact injury facilitates motor recovery and acquisition of spatial learning," Behavioural Brain Research, vol. 194, no. 1, pp. 79-85, 2008.

[3] J. B. Cohn, K. Rickels, and J. F. Steege, "A pooled, double-blind comparison of the effects of buspirone, diazepam and placebo in women with chronic anxiety," Current Medical Research and Opinion, vol. 11, no. 5, pp. 304-320, 1989.

[4] H. L. Goldberg and R. J. Finnerty, "The comparative efficacy of buspirone and diazepam in the treatment of anxiety," American Journal of Psychiatry, vol. 136, no. 9, pp. 1184-1187, 1979.

[5] S. M. Murphy, R. Owen, and P. Tyrer, "Comparative assessment of efficacy and withdrawal symptoms after 6 and 12 weeks' treatment with diazepam or buspirone," British Journal of Psychiatry, vol. 154, pp. 529-534, 1989.

[6] D. L. Sontheimer and A. Z. Ables, "Is imipramine or buspirone treatment effective in patients wishing to discontinue long-term benzodiazepine use?" Journal of Family Practice, vol. 50, no. 3, p. 203, 2001.

[7] P. Bller, R. Bergeron, and C. De Montigny, "Selective activation of postsynaptic 5-HT1A receptors induce srapid antidepressant response," Neuro-Psychopharmacology, vol. 16, no. 5, p. 333, 1997. 


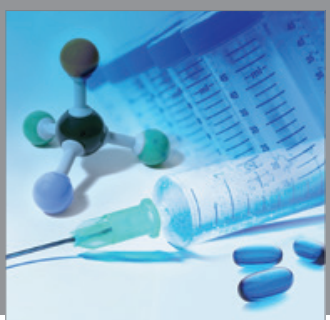

International Journal of

Medicinal Chemistry

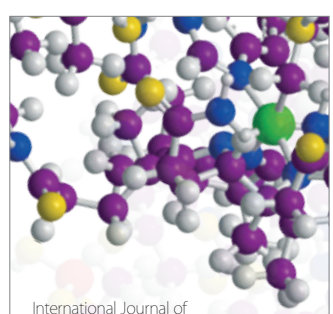

Carbohydrate Chemistry

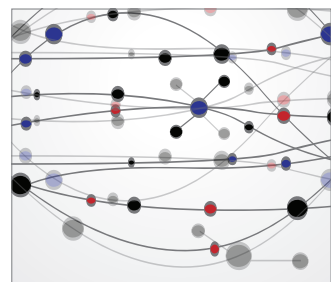

The Scientific World Journal
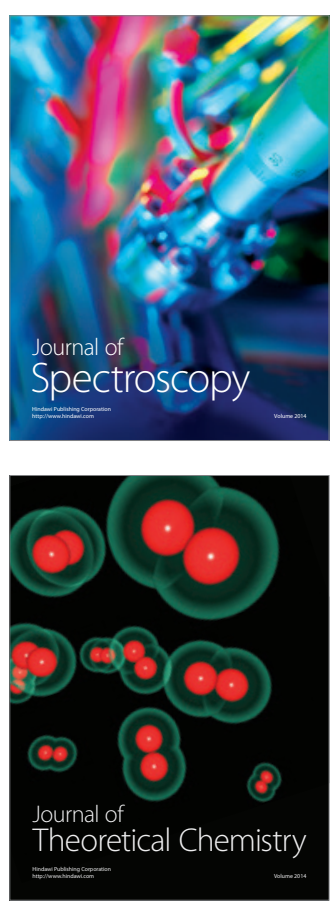
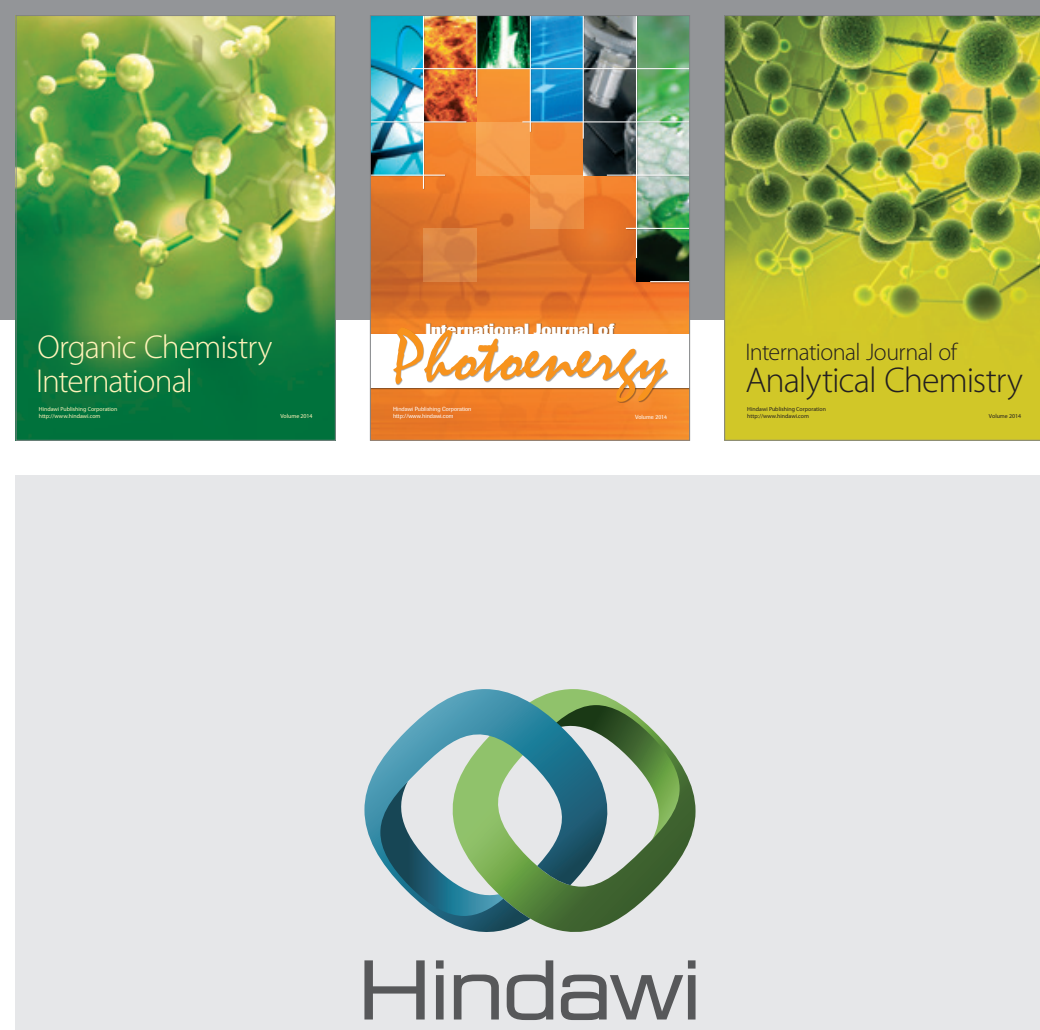

Submit your manuscripts at

http://www.hindawi.com
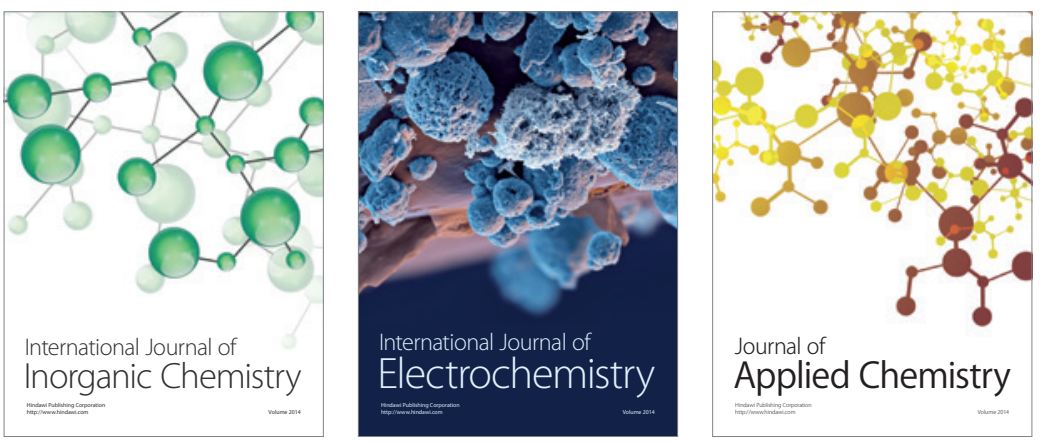

Journal of

Applied Chemistry
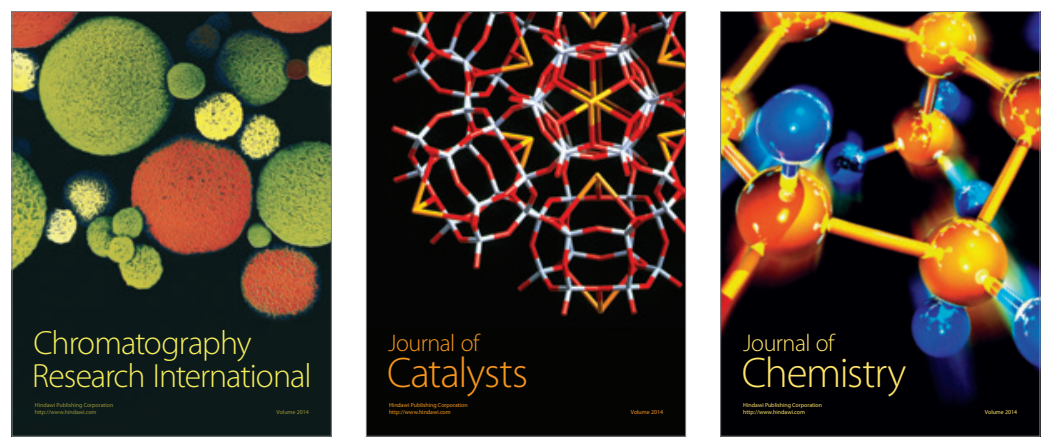
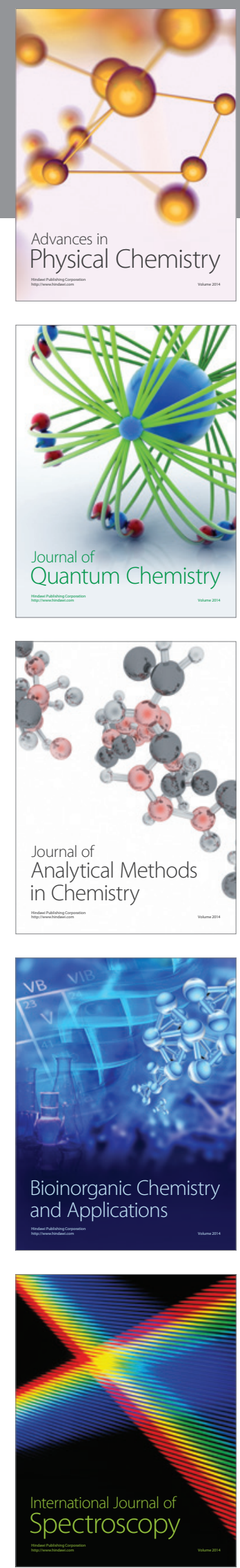